585 AeroVironment, Inc.

c 3 Alden Electronics

589 Belfort Instrument Co.

c 4 Bendix Corporation

597 Contel Corporation

595 D. Reidel Publishing Co.

c 2 Science Associates

601 Viking Press

AMS Notices (Publications, Preprints, etc.)

595 The Dynamic Meteorology of the Stratosphere and Mesosphere

604 Curricula in the Atmospheric and Oceanographic Sciences: 1976

611 Workshop on Micrometeorology

620 Abstracts, Second Conference on Atmospheric Radiation

620 Preprint Volume, 16th Radar Meteorology Conference

657 Abstracts, Special Regional Weather Modification

659 Publications of the American Meteorological Society

668 Preprint Volume, Fourth Conference on Probability and Statistics

668 Employment Announcements

The deadline for advertising insertion orders is the 15th, two months prior to date of issue. Orders received after deadline are subject to space availability. Deadline for copy and/or plate is the lst day of month, one month prior to date of issue. For advertising information contact: Lilly G. Albo, American Meteorological Society, 45 Beacon Street, Boston, Mass. 02108. Tel. 617-227-2425.

\section{employment announcements}

The American Meteorological Society issues employment announcements monthly, setting forth opportunities for positions in the atmospheric and oceanographic fields. The employers describe the prerequisites and requirements for the openings.

Members and nonmembers of the AMS may subscribe to the announcements. The subscription price per annum for twelve monthly issues is $\$ 5$ for AMS Members and Associate Members, $\$ 2$ for AMS Student Members, and $\$ 25$ for non-members.

The purpose of the Employment Announcements is to provide a means by which those seeking positions in the atmospheric and related fields and those requiring personnel to fill such openings may have a convenient means of communication. Organizations that wish to avail themselves of this service should contact Jean Cooper, American Meteorological Society, 45 Beacon Street, Boston, Mass. 02108 (617-227-2425), for details and charges.

\section{FOURTH CONFERENCE} ON

\section{PROBABILITY AND STATISTICS}

\section{IN ATMOSPHERIC SCIENCES}

Nov. 18-21, 1975

Tallahassee, Fla.

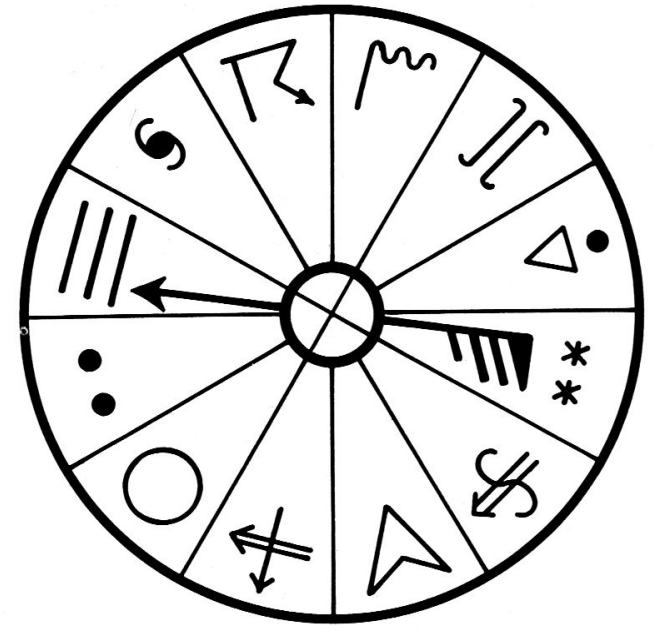

The Fourth Conference on Probability and Statistics in Atmospheric Sciences, sponsored by the American Meteorological Society and cosponsored by the Florida State University, was held November 18-21, 1975, in Tallahassee, Florida. The 43 papers "stress recent developments in probability and statistics of importance to atmospheric scientists and innovative uses of probabilistic and statistical methodology in atmospheric science." Topics include:

Statistical and Statistical-Dynamical Forecasting - Statistical and Probabilistic Forecasting - Application of Statistics to Weather Modification • Analysis and Assimilation of Meteorological Fields - Time Series and Spectral Analysis - Markov Chains and Persistence - Application of Statistics to Satellite Meteorology - Air Pollution and Micrometeorology • Data Analysis

$$
\begin{array}{ll}
216 \text { pages } & \$ 15 \text { AMS Members } \\
& \$ 20 \text { Nonmembers }
\end{array}
$$

Send orders and remittance to:

\section{AMERICAN METEOROLOGICAL SOCIETY}

45 Beacon Street, Boston, Mass. 02108 